\title{
The Development of e-Hub Supply Chain Management Portal System for Construction Projects
}

\author{
Yu-Cheng LIN ${ }^{a}$, and H. Ping TSERNG ${ }^{b}$ \\ a Ph.D Candidate, Department of Civil Engineering, National Taiwan Univ., Taipei, \\ Taiwan. \\ yucheng@ce.ntu.edu.tw \\ b Associate Professor, Department of Civil Engineering, National Taiwan Univ., Taipei, \\ Taiwan. \\ hptserng@ce.ntu.edu.tw
}

\begin{abstract}
Construction projects are composed of a large number of contractors, subcontractors, and suppliers that comprise the project supply chain. Construction supply chain management as a field of study concerns itself with improving the coordination of these firms to improve project performance along various metrics such as speed, cost, reliability, quality, etc. In order to link the construction supply chain well, information sharing is a basic requirement and function in the supply chain management system. Without the information sharing, the supply chain partners cannot communicate each other and connect construction operation to synchronize and streamline all communications among the company. However, the rise of the interconnectivity between different information systems over the Internet impacts construction processes, thus the defective characteristics of the construction industry can be overcome by an assistance of technology. This paper describes the prototype and system of e-Hub Construction Supply Chain Management (eHub-ConSCM) System for information shared service in executing the construction projects. The information needs for eHubConSCM System are illustrated, a general system architecture is describe and the implementation of eHubConSCM system is presented.
\end{abstract}

KEYWORDS: Supply Chain Management; Information Sharing; Construction Industry

\section{INTRODUCTION}

Supply chain management is one of the leading business process re-engineering, cost-saving and revenue enhancement strategies in use today. The Internet has already had a tremendous impact on the field of supply chain management, and there is more to come. However, it is not easy to develop a formalized SCM system in the construction industry because production line is changed with every project. Usually, a general contractor is the main coordinator in the construction processes involved many participants and with complicated interface each other. Therefore, it is necessary and important for a general contractor to build a Huboriented information center to collect and manage the newest updated information and data from other project-related participants. In practice, interactions among participating project teams are limited only to closely related teams. This is because it is almost impossible to communicate with dozens of subcontractors, suppliers, and hundreds of sub-suppliers in a single project.
Furthermore, since all participants have their own competing goals and objectives, the lack of coordination and information sharing among them leads to the distorted demand fluctuation known as the "Bullwhip effect". Such fluctuation could result in poor project plan and management, excessive inventory, insufficient or excessive capacities, uncertain production planning, and high costs for correction such as for expedited shipment and overtime. In order to avoid the mentioned problem, a hub-based portal system is presented and developed to avoid the problem happened by integrated supply chain management concept and advanced Internet technologies.

\section{PROBLEM STATEMENTS}

The application of supply chain management for the construction industry is more difficult than other industries due to its own unique characteristics. When considering the traditional fax/phone communication among the participants, the complexity and difficulty of information 
exchange is evident. In the traditional construction supply chain, there are many separate material flows and information flows. Each of these flows is charged with making forecasting and production and ordering decisions based on the downstream demands, internal capacity and upstream constraints in the chain with which it interfaces.

Because of an inability or unwillingness to share information, the demand signal is often distorted as it flows upstream leading to a phenomenon known as the "bullwhip effect" (Lee et al. 1997). Procter \& Gamble first coined the bullwhip effect during a replenishment pattern study for disposable diapers (Nahmias 1997). Procter \& Gamble noticed that even though diaper demand was relatively stable, the upstream orders were amplified. In construction, variability increases upstream in the supply chain as each node creates its own forecast, schedule, inventory decision and material requirements plan. This effect is compounded by the fact that ordering is typically based on the immediate needs of the downstream customer. As a result, manufacturers and suppliers carry far more inventory than necessary. By limiting coordination to tradition communication, the supply chain is unable to flexibly meet the demands of the end customer. Effective operational control of a supply chain requires centralized coordination of key data. For construction industries, this typically has meant forecasts, inventory status at all sites, backlogs, production plans, supplier delivery schedules and pipeline inventory. In other words, supply chain integration requires all participants in the network to communicate and share detailed, current information.

\section{SYSTEM DESIGN AND ANALYSIS}

Information technology can help to overcome the traditional construction supply chain problems. Electronic exchange of information leads to reduction of errors and increased efficiency of the operation processes. When all participants can analyze their projects based on the information sharing from related-participants in the supply chain, the negative effects of uncertainty can be mitigated in theory. In practice, however, the exchange of information between participants is not as easy as it seems. Many different systems and standards are used, the number of peer-to-peer relations with other participants in the network is usually too large to manage, most systems are not open for easy exchange of information with other systems. Furthermore, most participants are very reluctant to share information with other participants in the first place.

A portal represents a solution to overcome these problems. Standardized interactions with one portal are easier to manage than are many peer-topeer relationships. The portal provides an organization with a single, unified database, linked across all functional systems, both within the organization and between the organization and its major supply chain partners. This paper aims at addressing the quick respond supervision and environment special for general contractor, subcontractors and their suppliers, presenting a web based solution as a support. We present Hubbased construction supply chain management portal system to provide all project-involved participants to provide information sharing service and data center management. Finally the effectiveness of a Hub-oriented SCM system is verified based on the survey by users.

\section{SYSTEM IMPLETMENTATION}

Increasingly, all the project participants understand the importance of information sharing during the project implement. A major objective of this paper is to illustrate the application in the construction supply chain and explain the framework to link the whole supply chain across all participants, integrated Internet technologies. The portal uses middleware technology to integrate disparate sources of information from participants. Also, the portal provides a secure intelligent online gateway with access to multimedia collaboration functions. With the portal and its associated tools, managers and engineers of each participant can conduct effective monitor and controlling activities for the project. The presented system showed how the designed analysis modules in the Hub-ConSCM portal system could be applied in the construction supply chain industries. The main benefits of using this system include improved the decision-making performance, inventory availability and reduced life cycle costs by providing the right information to the right people to make the best decisions in real time updated situation. The portal solution uses middleware to link systems and participants together and to create a seamless supply chain for system users while hiding the transactional level processing complexity from them. In order to make the system more effectively, the system is designed and developed the three layers. They are the Portal Layer, the business logic Layer and the Data Access Layer (see Fig 2). After the user 
logging in, user is taken to the respective interface wherein information is classified under sections of 'Company Info', and the related entity. The architecture used is a three tiers model, with HTML, JavaScript / servlets forming the user interface (presentation layer), the connection layer (JSP / JDBC) (Business Logic Layer) and the SQL RDBMS forming the Data Access Layer.

\subsection{Presentation Layer}

Presentation Layer is responsible for the presentation of data, receiving user events and controlling the user interface. HTML/DHTML with JavaScript is used for developing User Interface Screens. Furthermore, Uses Socket class to communicate with server and Client side validations are done through JavaScript.

\subsection{Business Logic Layer}

Business logic layer is created using ServerSocket class. It keeps listening for the clients to communicate with it for service. Every time a new client logs on, a separate session is created for processing its The following modules are developed in the Business Logic Layer (see Figure 2):

1. Project control module

2. Project Information module

3. Resource Management

4. Tracing Management

5. Information Analysis

6. Inventory Management

7. Administration Management

The description of each module is summarized in the Table 1. These function modules are special designed for the characteristics of construction projects.

\subsection{Data Access Layer}

Data Access Layer tier is responsible for data storage. Relational database systems and MS SQL 2002 is adopted in the system. All the changes to the database occurs after the exceptions are caught, handled and confirmation for changes received. Also, System is developed to backup the system Database automatically whenever required.

\section{CONCLUSIONS}

The Hub-SCM portal system is developed to manager and control the project for the projectinvolved participants in the hub-center based environment. The Hub-ConSCM portal system allows more effective management of the construction supply chain by providing the information sharing services to project-involved participants and allowing the links of the supply chain to work together to produce the best possible outcomes (see Figure3). The portal system also allows participants to have access newest information and make right decision in their own office without using traditional communication ways. Most important, the portal supports the analysis function for all participants that can use these function directly on the web platform. This allows more complex, integrated decision-making than is possible with separate systems that are, in effect, islands of information. Finally, the system is scalable, allowing more users to be connected as required. This system is applied in the Taiwan real case to evaluate the practice suitability. Interview feedback with general contractor and participants are summarized to modify further system functionality and prototype. The main benefits of the system based on the interview feedback are following:

1. Improvement in the data consistence

2. Faster response and faster trading cycle

3. Maximize business process efficiency

4. A proven track record in SCM

5. Reduce inventory costs

6. Increase visibility and control

7. Automate workflow \& information exchange

8. Increase resource utilization

9. Enhance partner communication

\section{RECOMMANDATIONS}

In the future, internet-based technologies such as XML data formatting and peer to peer system architecture will be considered to use in the system for multilateral collaboration among networks of suppliers, subcontractors, and general contractor in the construction project. Also, the whole data source in eHub-ConSCM system should be integrated with ERP (Enterprise Resource Planning) system. It is necessary and important to connect the two systems together for enterprise information backbone.

\section{REFERENCES}

[AEGIS] AEGIS, (1999) "Mapping the Building and Construction Product System in Australia", Research Report, Australian Expert Group in Industry Studies, University of Western Sydney, 
Department of Industry, Science and Technology, Australian Commonwealth Government.

[Al-Sudairi] Al-Sudairi, A. A., Diekman, J. E., Songer, A. D., and Brown, H. M. (1999). "Simulation of construction processes: traditional practices versus lean construction." Proceedings of IGLC-7, Berkeley, CA, July 26-28, 1999, 39-50.

[Alter] Alter, C. and Hage, J. (1993.). Organizations Working Together. Newbury Park, Calif., Sage Publications.

[Arntzen] Arntzen, B. C., Brown, G. G., Harrison, T. P., and Trafton, L. L. (1995). "Global supply chain management at Digital Equipment Corporation." Interfaces, 25(1), 69-93.

[Bowersox] Bowersox, D. J., D. Closs, M. B. Cooper. (2002). Supply Chain Logistics Management, Boston, McGraw-Hill.

[Callaghan] Callaghan, J. (1998). Supply Networks: Project ION - Literature Review of Supply Networks, University of Bath. 1998.

[Boyson] Boyson, S., Corsi, T., Dresner, M., Harrington, L., 1999. Logistics and the Extended Enterprise. John Wiley \& Sons,New York.

\section{Table 1. System Function}

\begin{tabular}{|c|c|}
\hline Category of Modules & Description of Modules \\
\hline Project Control & $\begin{array}{l}\text { Provide the participants to trace the project-related activities in schedule control. } \\
\text { Participants can check and analyze the schedule information by the web-based } \\
\text { portal. }\end{array}$ \\
\hline Project Information & $\begin{array}{l}\text { Provide the participants to download the project-related information (drawings and } \\
\text { specification) directly on the web. Furthermore, These project-related documents } \\
\text { and information can be contained and updated centralizely. }\end{array}$ \\
\hline Resource Management & $\begin{array}{l}\text { Provide the general contractor to trace and manage the project-related resources } \\
\text { using in projects. Users can check and understand which resource is available to } \\
\text { use and make reservations directly on the system. }\end{array}$ \\
\hline Tracing Management & $\begin{array}{l}\text { Provide the general contractor to trace the project-related activities or resources in } \\
\text { the project production and deliver process. Participants can enter and update the } \\
\text { production information to share the information with other participants. }\end{array}$ \\
\hline Information Analysis & $\begin{array}{l}\text { Provide the general contractor to analyze the project-related supply condition } \\
\text { situation based on the information shared from activity-involved participants. } \\
\text { Participants can check the information by the web-based portal. }\end{array}$ \\
\hline Inventory Management & $\begin{array}{l}\text { Provide the general contractor to trace the project-related materials and elements in } \\
\text { the portal. General Contractor can check and manager the inventory status provided } \\
\text { by site engineers. }\end{array}$ \\
\hline Administration Management & $\begin{array}{l}\text { Provide the administrator to control the project-related participants to use this } \\
\text { system. Participants can apply authority directly from the portal. }\end{array}$ \\
\hline
\end{tabular}




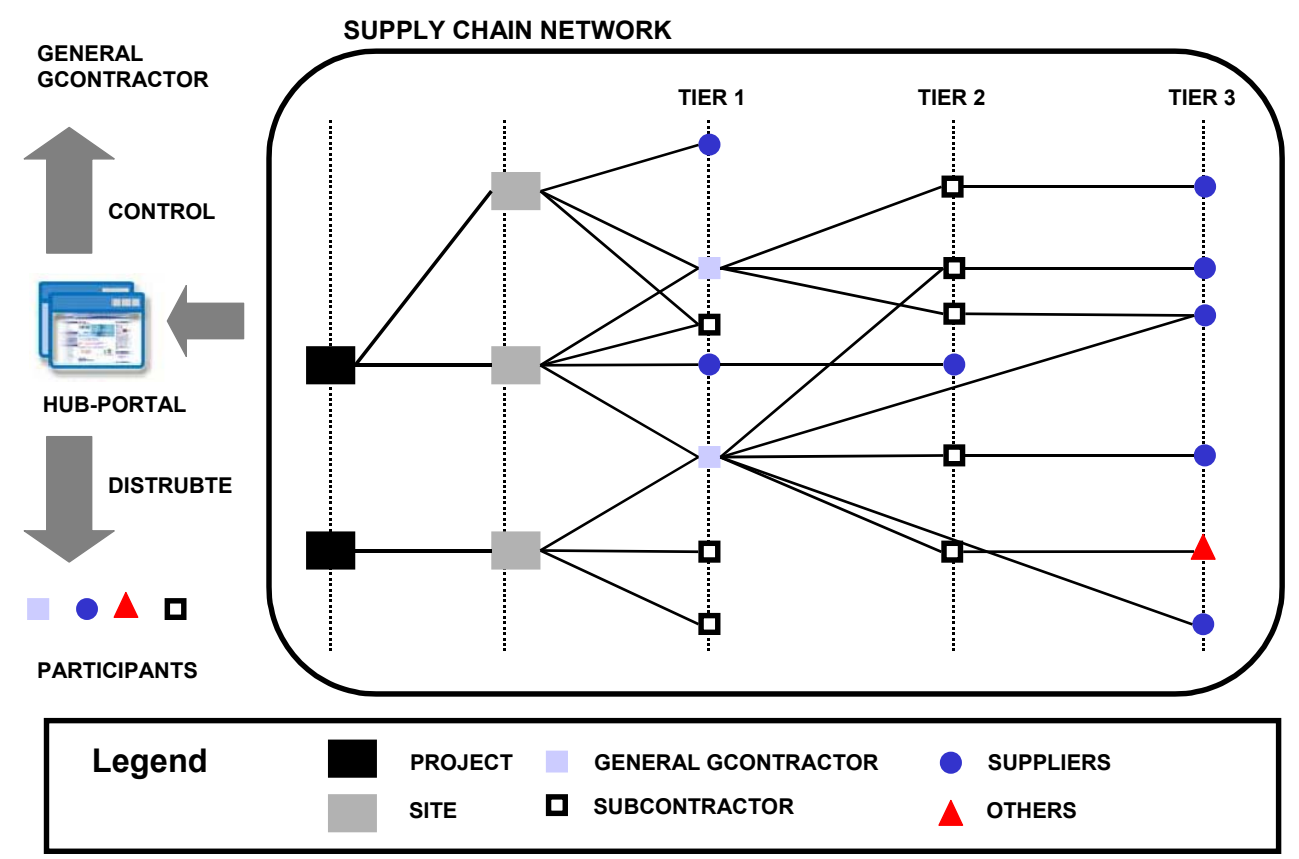

Figure 1. System Concept and Framework.

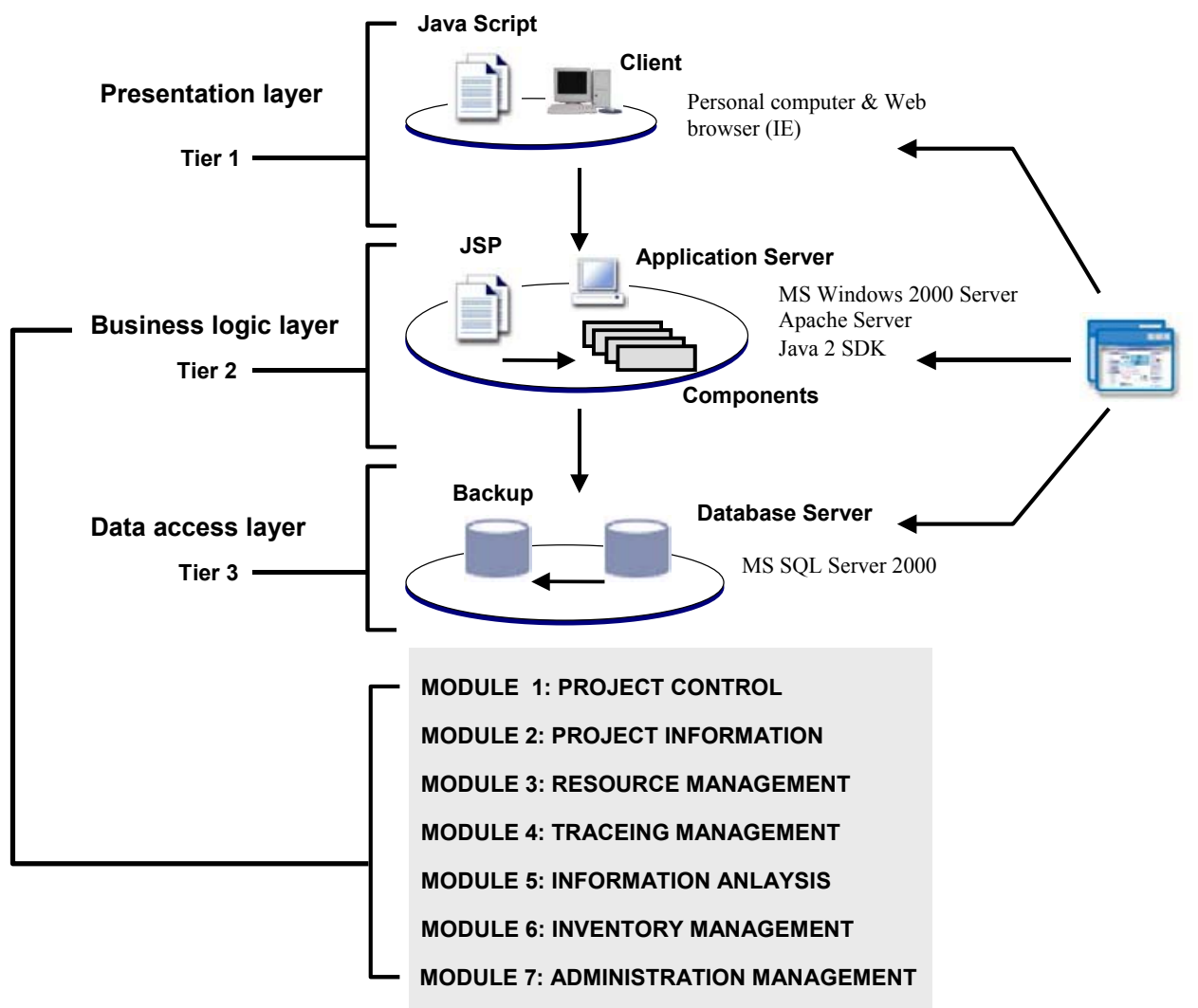

Figure 2. System Architecture. 


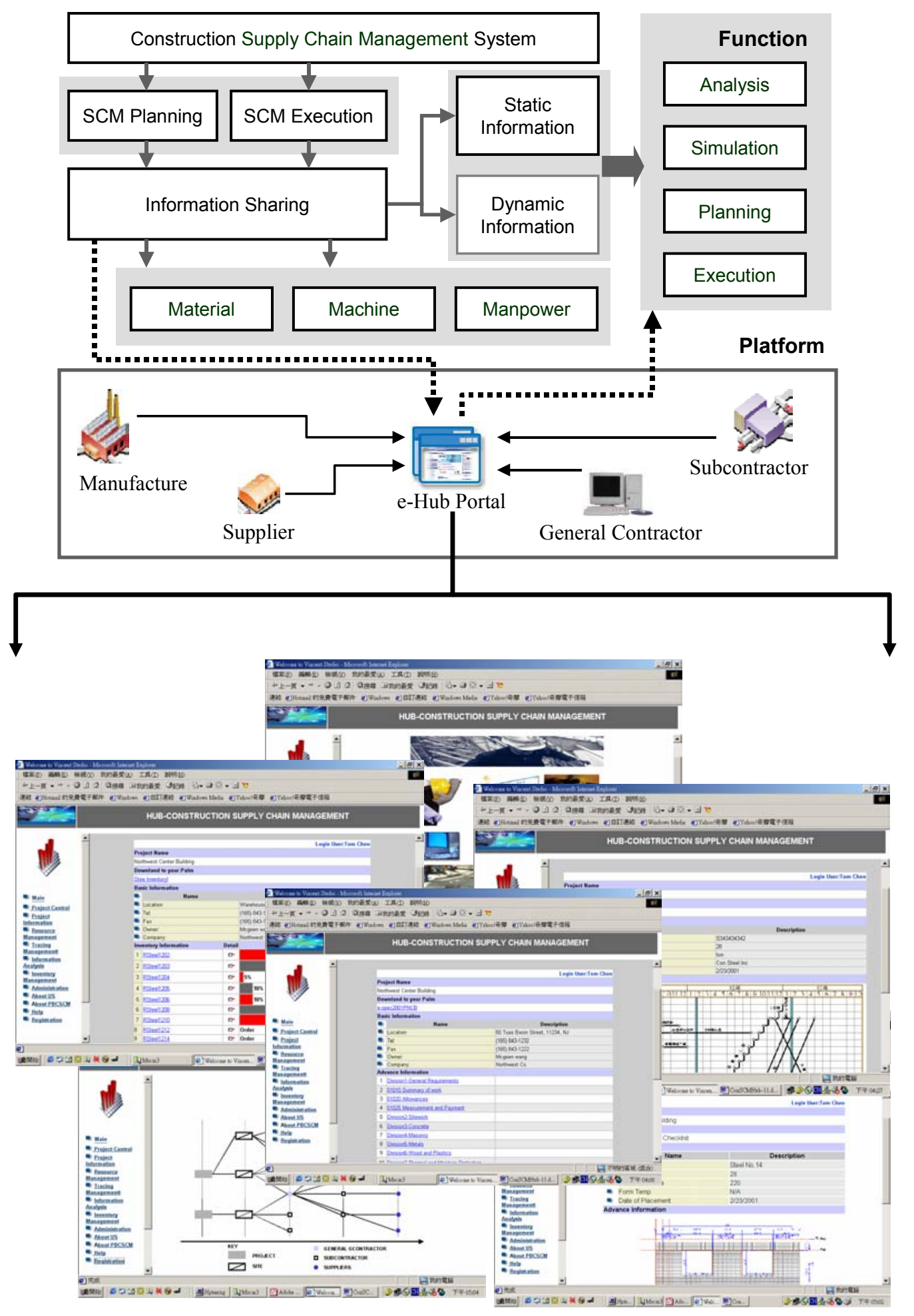

Figure 3. The Framework of Construction Supply Chain Management. 